\title{
The Effect of Reservoir Heterogeneity on Gas Production from Hydrate Accumulations in the Permafrost
}

\author{
Matthew T. Reagan ${ }^{1}$, SPE, Michael B. Kowalsky ${ }^{1}$, George J. Moridis ${ }^{1}$, SPE, and Suntichai Silpngarmlert ${ }^{2}$, SPE \\ ${ }^{1}$ Lawrence Berkeley National Laboratory, 1 Cyclotron Rd., Berkeley, CA 94720 \\ ${ }^{2}$ ConocoPhillips, 600 North Dairy Ashford, Houston, TX 77252
}

\begin{abstract}
The quantity of hydrocarbon gases trapped in natural hydrate accumulations is enormous, leading to significant interest in the evaluation of their potential as an energy source. Large volumes of gas can be readily produced at high rates for long times from methane hydrate accumulations in the permafrost by means of depressurization-induced dissociation combined with conventional technologies and horizontal or vertical well configurations. Initial studies on the possibility of natural gas production from permafrost hydrates assumed homogeneity in intrinsic reservoir properties and in the initial condition of the hydrate-bearing layers (either due to the coarseness of the model or due to simplifications in the definition of the system). These results showed great promise for gas recovery from Class 1,2, and 3 systems in the permafrost. This work examines the consequences of inevitable heterogeneity in intrinsic properties, such as in the porosity of the hydrate-bearing formation, or heterogeneity in the initial state of hydrate saturation. Heterogeneous configurations are generated through multiple methods: 1) through defining heterogeneous layers via existing well-log data, 2) through randomized initialization of reservoir properties and initial conditions, and 3) through the use of geostatistical methods to create heterogeneous fields that extrapolate from the limited data available from cores and well-log data. These extrapolations use available information and established geophysical methods to capture a range of deposit properties and hydrate configurations. The results show that some forms of heterogeneity, such as horizontal stratification, can assist in production of hydrate-derived gas. However, more heterogeneous structures can lead to complex physical behavior within the deposit and near the wellbore that may obstruct the flow of fluids to the well, necessitating revised production strategies. The need for fine discretization is crucial in all cases to capture dynamic behavior during production.
\end{abstract}

\section{Introduction}

Objective. This investigation is part of an effort led by the U.S. Department of Energy to identify appropriate targets for a long-term field test of production from permafrost-associated hydrate deposits (Boswell et al, 2008). The main objective of this study is to determine through sensitivity analysis the possible effects of deposit heterogeneity on productivity, and assess the production strategies required to achieve economically viable production.

Background. Gas hydrates are solid crystalline compounds in which gas molecules (referred to as guests) occupy the lattices of host ice crystal structures. Their formation and dissociation is described by the general equation:

$\mathrm{G}+N_{H} \mathrm{H}_{2} \mathrm{O}=\mathrm{G} \cdot N_{H} \mathrm{H}_{2} \mathrm{O}$,

where $N_{H}$ is the hydration number, and $\mathrm{G}$ is a hydrate-forming gas. Natural hydrates in geological systems contain $\mathrm{G}=\mathrm{CH}_{4}$ as their main gas ingredient, and occur in two distinctly different geologic settings where the necessary conditions of low $T$ and high $P$ exist for their formation and stability: in the permafrost and in deep ocean sediments.

The quantity of $\mathrm{CH}_{4}$ contained hydrates is the subject of continuing debate, and estimates vary widely between $10^{15}$ and $10^{18}$ $\mathrm{ST} \mathrm{m}^{3}$ (Sloan and Koh, 2008; Milkov, 2004; Klauda and Sandler, 2005). The general consensus is that this quantity is huge, easily exceeding the total energy content of the known conventional fossil fuel resources. Even if only a fraction of the most conservative estimate of the resource is recoverable, the quantities involved are large enough motivate further evaluation of hydrates as an energy source (Makogon, 1987; Dallimore et al., 1999; 2005). As result, many studies have evaluated the technical and economic feasibility of gas production from natural hydrate accumulations (Moridis, 2003; Sun and Mohanty, 2005; Moridis and Sloan, 2007; Moridis and Reagan, 2007a;b;c; Kurihara et al., 2009; Moridis et al., 2009).

Gas can be produced from hydrates by inducing dissociation using any of the three main dissociation methods (Makogon, 1997): (1) depressurization below the hydration pressure $P_{e}$ at the temperature T, (2) thermal stimulation, based on raising $T$ above the hydration temperature $T_{e}$ at the prevailing pressure $P$, and (3) the use of inhibitors (such as salts and alcohols) that shift the $P_{e}-T_{e}$ equilibrium. However, multiple studies (Moridis and Reagan, 2007a;b; Reagan et al., 2008) have demonstrated the depressurization is typically the most effective, efficient, and economically viable method to dissociate hydrates in situ and enable production of hydrate-derived methane. Thermal stimulation is reserved for localized control of secondary hydrate or ice formation, or for the initial dissociation of hydrate around the well production interval (Moridis and Reagan, 2007b), as 
it is not effective as the sole method of inducing dissociation at rates conducive to economical production (Moridis and Reagan, 2007a).

Mount Elbert unit D. Unit D at the Mount Elbert site (Moridis et al., 2010) is a relatively shallow, cold, permafrostassociated Class 3 deposit, involving a single hydrate-bearing layer (HBL) confined by near-impermeable top and bottom boundaries with no underlying zone of mobile fluids. Simulations performed by Moridis and Reagan (2007a) indicated that depressurization would be the most effective production method, due to its simplicity and technical and economic effectiveness. We focused exclusively on production under a constant bottomhole pressure $P_{w}$ regime because earlier studies (Moridis and Reagan, 2007a; Reagan et al., 2008) had indicated this to be the most promising option for production from Class 3 deposits with similar attributes. The geology and geochemistry of hydrate-bearing formations on the North Slope of Alaska are described in considerable detail in a number of publications (Bird and Magoon, 1987; Collett, 1993) and the formulation of the 2-D vertical and horizontal well descriptions is documented in detail by a paper discussing the base case and production strategy for this particular site (Moridis et al., 2010). Recovered cores revealed pore water geochemistry, microbiology, gas chemistry, petrophysical properties, and thermal and physical properties (Boswell et al., 2009), and well $\log$ surveys located two reservoir-quality sandy hydrate-bearing sections with high $S_{H}(60 \%$ to $75 \%$ ) (Collett, 2007). As in the previous paper, these data are used to construct numerical models for the assessment of production to inform future field tests at the site.

The unit $\mathrm{D}$ formation has a HBL beginning at a depth of $z=-616.6 \mathrm{~m}$. The deposit is about $11.3 \mathrm{~m}$ thick and is bounded by nearly impermeable shale layers. The pressure at the top of the HBL is $P_{T}=6.386 \mathrm{MPa}$, but the temperature is low $\left(T_{T}=2.3\right.$ ${ }^{\circ} \mathrm{C}$ and $T_{B}=2.6{ }^{\circ} \mathrm{C}$ at the HBL top and bottom). This low temperature has lead to concerns about the productivity of the deposit (Moridis et al., 2010) and suggests that particular attention must be paid to production rates, strategies, and the formation of secondary hydrate during production. The properties and initial conditions of unit D are listed in Table 1, and a simplified well log for the Mount Elbert-01 location is presented in Figure 1.

\section{The Numerical Models and Simulation Approach}

The numerical simulation code. We used the massively parallel TOUGH+HYDRATE $(\mathrm{pT}+\mathrm{H})$ simulator (Moridis et al., 2008b; Zhang et al., 2008) to simulate production from the Unit D system. pT $+\mathrm{H}$ can model all the known processes involved in the system response of natural $\mathrm{CH}_{4}$-hydrates in complex geologic media, including the flow of fluids and heat, the thermophysical properties of reservoir fluids, thermodynamic changes and phase behavior, and the non-isothermal chemical reaction of $\mathrm{CH}_{4}$-hydrate formation and/or dissociation, which can be described by either an equilibrium or a kinetic model (Kim et al., 1998; Clarke and Bishnoi, 2001; Moridis and Kowalsky, 2008). pT+H accounts for heat and up to four mass components $\left(\mathrm{H}_{2} \mathrm{O}, \mathrm{CH}_{4}, \mathrm{CH}_{4}\right.$-hydrate, and water-soluble inhibitors such as salts or alcohols) that are partitioned among four possible phases: gas, aqueous liquid, ice, and hydrate. The $\mathrm{pT}+\mathrm{H}$ code can describe all the 15 possible thermodynamic states (phase combinations) of this $\mathrm{CH}_{4}+\mathrm{H}_{2} \mathrm{O}$ system and model any combination of the three hydrate dissociation methods. It can handle the typical phase changes, state transitions, strong nonlinearities, and steep solution surfaces of hydrate dissociation problems.

System geometry. The geologic system in this study is a typical Class 3 deposit with a 11.3-m-thick HBL overlain and underlain by nearly impermeable boundaries. As in earlier studies of systems of this type and scale (Moridis and Reagan, 2007a;b; Moridis et al., 2008a; Moridis et al., 2010) the simulation domain was extended $30 \mathrm{~m}$ into the overburden and underburden, a distance that was deemed sufficient to allow accurate heat exchange with the deposit during the production period. Previous work (Moridis et al., 2010) investigated the performance of both a single vertical and a single horizontal well producing from equivalent sections (cylindrical and rectangular) of the same hydrate deposit, using the same surface area and including the same hydrate volume in each simulation configuration. As performance of the horizontal well was shown to be superior to the performance of the vertical well in all cases, this sensitivity studies focuses only on the horizontal well case. The geometry and well configuration of the system is shown in Figure 2 . The horizontal well radius of $r_{w}=0.1 \mathrm{~m}$ was placed at the top of the HBL $\left(z_{W}=0 \mathrm{~m}\right)$ to capitalize on gas buoyancy and accumulation at this location, and to minimize water production.

Domain discretization. For maximum accuracy, and leveraging experience from previous simulation studies (Moridis and Reagan, 2007a;b) very fine discretization was used. A 2-D slice of the domain was discretized into $200 \times 300=60,000$ gridblocks in $(x, z)$. Discretization along the $z$-axis was uniform $(\Delta z=0.1 \mathrm{~m})$ within the HBL and its immediate vicinity, but non-uniform ( $\Delta z$ increasing away from the HBL) near the top and bottom of the domain. Discretization along $x$-axis was nonuniform, increasing logarithmically from $x_{0}=r_{w}$ to $L_{x}$, with $\Delta x_{0}=0.05 \mathrm{~m}$. The fine discretization is important for accurate predictions when solid phases such as ice and hydrates are involved (Moridis and Reagan, 2007a;b) and to capture important processes near the wellbore. We used only a single slice of unit thickness on the $(x, z)$ plane, i.e., perpendicular to the horizontal well. Implicit in this approach is the assumption of uniformity along the well length $L_{w}$, i.e., along the $y$-axis. This assumption allows high-definition in the description of the system behavior without resulting in a prohibitively large grid, 
although in this case it also constrains any modeled heterogeneity to uniformity along the $y$-axis as well. Assuming an equilibrium reaction of hydrate dissociation during this long-term production process (Kowalsky and Moridis, 2007), and including salinity of the formation water, the simulation involved the solution of 240,000 coupled equations.

System properties and well description. The hydraulic and thermal properties of the various geological media (the HBL and the confining layers) for unit $\mathrm{D}$, as well as the initial conditions, were obtained from data based on the first field test at the site (Anderson et al., 2010) and are listed in Table 1. The base case (Moridis et al., 2010) assumed that the initial hydrate and aqueous saturations $\left(S_{H}\right.$ and $\left.S_{A}\right)$ were uniform within in the HBL, and that the overburden and underburden had the same properties. For this study, we use the identical Base Case, including the same mesh, geological parameters, relative permeability relationships, and capillary pressure relationships. The location of the horizontal well is fixed at the top of the HBL, at $z_{W}=0 \mathrm{~m}$ (Figure 2). A summary of simulation parameters can be found in Table 1. Also, as in the base case and previous simulation studies, we represented the well using Darcy flow through a pseudo-porous medium. Earlier studies have shown the validity of this approximation (Moridis and Reagan, 2007a;b). This pseudo-medium had $\phi=1.0$, a very high $k=$ $10^{-9} \mathrm{~m}^{2}\left(=1,000\right.$ Darcies), a capillary pressure $P_{c a p}=0$, a relative permeability that is a linear function of the phase saturations in the wellbore, and a low (but non-zero) irreducible gas saturation $S_{i r G}=0.005$ to allow the emergence of a free gas phase. Three gridblocks represented the $(x, z)$ half-cross section of the producing outer radius of the horizontal well.

Initial and boundary conditions. No-flow conditions for fluid and heat are applied at the reservoir outer boundaries (at $x=$ $L_{x}=L_{y} / 2$ ), implying the presence of other wells with the same characteristics in adjacent sections of the hydrate deposit on the same spacing patterns. Initial conditions were generated through the initialization process described in earlier publications (Moridis and Reagan, 2007a;b) and the system was brought to thermal, chemical, and hydrostatic equilibrium for the full 2-D system at the same conditions described in Moridis et al., 2010. The uppermost and lowermost gridblock layers were treated as constant- $T$ boundaries, and the shales in the overburden and underburden were treated as impermeable (Table 1).

As depressurization was selected as the most promising dissociation strategy, we applied a constant bottomhole pressure $P_{w}$ at the well. The well itself is treated as an internal boundary with a constant $P_{w}=3.0 \mathrm{MPa}$, a thermal conductivity $k_{\Theta}=0$ $\mathrm{W} / \mathrm{m} / \mathrm{K}$, a realistic constant temperature $T_{w}$. The pressure exceeds the pressure at the quadruple point, and eliminates concerns about flow blockages due to ice formation.

Heterogeneous initial conditions. The goal of this study is to assess the sensitivity of hydrate production to varying degrees and types of heterogeneity in the HBS. In order to isolate the effect on production of heterogeneity in a particular property, we examine several cases in which a single property in the HBS is made heterogeneous while the remaining properties are kept uniform. In reality there may be site-specific correlations between various properties, such as between the permeability and the porosity or between the porosity and the initial hydrate saturation. Such considerations are beyond the scope of the present sensitivity study, and we merely seek to isolate individual dependencies to help assess the characteristics that determine productivity for permafrost-associated hydrate resources. Our focus will be on heterogeneous hydrate saturation, $S_{H, 0}$, and also, to a lesser extent, heterogeneous porosity.

The first method for generating heterogeneous conditions uses a simple random field with no spatial correlation. For this purpose, the hydrate saturation for each gridblock in the mesh was assigned a random value from a uniform probability distribution ranging between 0.55 and 0.75 , with a mean of 0.65 . This new initial condition was brought to thermal and hydrostatic equilibrium before simulations began. We looked at a case with isotropic permeability $\left(k_{z}=k_{x}\right)$ and an anisotropic case with reduced permeability along the vertical axis $\left(k_{z}=0.1 k_{x}\right)$.

The second method of generating heterogeneity attempts to capture the inherent "layering" of the depositional system in unit D. Well log data for $S_{H, 0}$ (Figure 1) was interpolated, averaged, and binned along the $z$-axis $(\Delta z=0.1 \mathrm{~m})$, and then extended horizontally along mesh layers, such that saturations were constant along the $x$-axis. Again, for this configuration we looked at a case with isotropic permeability $\left(k_{z}=k_{x}\right)$ and an anisotropic case with reduced permeability along the vertical axis $\left(k_{z}=\right.$ $\left.0.1 k_{x}\right)$.

For a third method, we consider heterogeneity as represented by spatially correlated random fields. A geostatistical approach allows the creation of heterogeneous distributions of properties that are more realistic then purely random distributions and that are consistent with the limited amount of characterization data that are available for the site. Note again that we make the implicit assumption that the generated heterogeneous fields are uncorrelated with the other properties of the production model. Specifically, we use GSLIB (Deutsch and Journel, 1992) to perform sequential Gaussian simulation (SGSIM) in order to generate unconditional realizations of the parameters of interest (the initial hydrate saturation or porosity distribution), which are then used as initial conditions in the production simulations. The SGSIM algorithm requires specification of the mean value and a semi-variogram model, which describes spatial correlation as a function of distance (Deutsch and Journel, 1992). Some of the required parameters were inferred from well log data (i.e., vertical profiles of hydrate saturation and porosity), while others are selected and varied as part of the sensitivity study. The semi-variogram model that best fits the 
available data is an exponential model, which includes the variance (or sill value) and the vertical and horizontal range (related to the correlation length) as input parameters. The vertical ranges (length scales) for the initial hydrate saturation and porosity were determined to be $0.95 \mathrm{~m}$ and $0.44 \mathrm{~m}$, respectively. Because there was insufficient information to determine the ranges in the horizontal direction, we assumed an anisotropy ratio of ten, giving values of $9.5 \mathrm{~m}$ and $4.4 \mathrm{~m}$, respectively, for the horizontal ranges of the initial hydrate saturation and porosity. Rather than using a variance value for each property, we consider different cases covering a range of possible values. Initial $\sigma^{2}=0.011$ for $S_{H}$ variations, while initial $\sigma^{2}=0.030$ for porosity variations (derived from the semi-variogram). The means of the initial hydrate saturation and porosity distributions were set to 0.65 and 0.40 , respectively, for all realizations. Once the realizations were generated, they were interpolated onto the existing mesh to generate a set of initial conditions for the simulation, which was again brought to hydrostatic, thermal, and chemical equilibrium before production simulations commenced. The 10 simulated scenarios are summarized Table 2.

Simulation process and outputs. The maximum simulation period for the Base Case was 50 years in order to investigate its very-long-term performance (Moridis et al., 2010). For this sensitivity study, we perform simulations of 8 to 50 years, with clearly unproductive systems "abandoned" earlier than productive configurations. Also, due to the particular response of hydrate-bearing systems to certain degrees of heterogeneity, some simulations were curtailed when both low production and extremely difficult numerical conditioning resulted in the us of an excessive amount of computer resources. In the course of the simulation, the following values were monitored: Spatial distributions of gas and hydrate phase saturations $\left(S_{G}\right.$ and $\left.S_{H}\right), P$, and $T$; Volumetric rate of $\mathrm{CH}_{4}$ production at the well and the volumetric rate of $\mathrm{CH}_{4}$ release from hydrate dissociation $\left(Q_{P}\right.$ and $\left.Q_{R}\right)$; Cumulative volume of $\mathrm{CH}_{4}$ produced at the well $\left(V_{P}\right)$; and cumulative mass of produced water $\left(M_{W}\right)$. In addition, a derived property, $R_{W G C}=M_{W} / V_{P}$, is computed to assess the total quantity of water removed per volume of gas produced at the well.

\section{Results: Production Rate}

Case 1: Base Case. For the full description of Case 1, or the base case, please refer to the previous paper by Moridis et al. (2010) as the analysis is too extensive to repeat here. However, relevant values and simulation outputs are reproduced within the following figures to allow for easy comparison between cases.

Case 2: Uniform distribution. Although this method has the least physical basis (particularly because the randomness is assigned per gridblock, and the grid does not represent real physical distinctions in the hydrate-bearing media), the results are included here for completeness and to highlight an extreme form of heterogeneity and its relationship to the physical behavior of hydrate-bearing systems. Figure 3 presents a comparison of production rates, $Q_{P}$, for all cases vs. the Base Case. In Figure 3 , we see that both Case 2a and Case $2 \mathrm{~b}$, the isotropic and anisotropic uniform distribution of $S_{H}$ leads to significantly lower $Q_{P}$, typically decreased by a factor of 5 or more. The rate does not exceed $0.007 \mathrm{ST} \mathrm{m} / \mathrm{s}(0.02 \mathrm{MMSCFD})$, a clearly unproductive outcome. Unlike the Base Case, which shows marked improvement in production rate after approximately 1 yr of production, Cases $2 \mathrm{a}$ and $2 \mathrm{~b}$ maintain low and economically unfeasible production for over $10 \mathrm{yr}$ with no evidence of improvement. Cumulative production, shown in Figure 4, is equally unpromising. Figure 5 presents the ratio of cumulative water removed, $M_{W}$, to the cumulative volumes of gas produced, $V_{P}-R W G C=M_{W} / V_{P}-$ for all cases vs. the Base Case. While production from hydrates is generally advantageous in terms of water production decreasing over time, Cases 2 a represents the worst case for large relative water production. The combination of very low gas production and high relative water removal suggest that such a scenario is hopeless. However, Case $2 \mathrm{~b}$ (anisotropic $k$ ) produces half the water per unit of recovered gas compared to the Case 2a, and $R_{W G C}$ approaches that of the Base Case. Despite the very low productivity, this scenario still suggests the benefits of horizontal stratigraphy in assisting the segregation of water from gas during production, although even a cursory glace at Figure 4 indicates that this is also at the expense of gas production itself - not a useful scenario.

Case 3: Layering. The initial conditions represented in Case 3 are particularly notable because they use actual well-log data to estimate initial hydrate saturations. Depositional systems like unit D are typically arranged in layers, and cores and well logs from this system and previously studied systems reflect this (Moridis and Reagan, 2007a;b; Moridis et al., 2010). The hydrate saturation profile shown in Figure 2 was interpolated onto the simulation mesh, with each horizontal layer in the system receiving a uniform saturation equal to the average saturation within the given $z$-range. Figure 3 again presents $\mathrm{CH}_{4}$ production rate vs. the Base Case. In this scenario, we see a significant improvement in $Q_{P}$ vs. $t$ vs. the Base Case for the first $32 \mathrm{yr}$ of production. At early times, the production rate is 4-5 times greater than the Base Case, and this advantage continues until $t=20 \mathrm{yr}$. The addition of anisotropy in $k$ provides some early advantages, but over time the Case $3 \mathrm{a}$ and Case $3 \mathrm{~b}$ follow a similar path. Cumulative production, $V_{P}$, in Figure 4 indicates that both Case $3 \mathrm{a}$ and $3 \mathrm{~b}$ result in roughly similar total produced quantities, both leading the Base Case throughout the 50 -yr production test. This behavior is not surprising. The layered structure, while offering roughly the same total quantity of hydrate in the reservoir, also offers zones of low hydrate saturation, and hence higher localized effective permeability. This permits the initial depressurization to propagate further into the deposit at earlier times, and later these higher- $k_{\text {eff }}$ layers provide convenient conduits for the transport of gas to the well. Anisotropy in $k$ may provide additional impetus for horizontal movement of gas through the formation (perhaps 
enhancing the formation of horizontal stratification in the remaining hydrate and/or any reformed hydrate), but areas of higher $k_{\text {eff }}$ between more saturated strata are most likely the prime advantage of producing from such a system. It should be noted here that Cases $3 \mathrm{a}$ and $3 \mathrm{~b}$, while the most productive, still reflect the somewhat poor productivity of this cold, shallow system at a maximum $Q_{P}$ of $0.08 \mathrm{ST} \mathrm{m} / \mathrm{s}$ or $0.24 \mathrm{MMSFCD}$. The cumulative ratio of water-to-gas, $R_{W G C}$, shown in Figure 5, clearly illustrates the benefits of these high- $k_{\text {eff }}$ channels, with the lowest $R_{W G C}$ of any scenario, coupled with a clear advantage in $R_{W G C}$ at early times.

Case 4: Geostatistical saturation. The process for generating statistical realizations consistent with a given variance and correlation length was described in the previous section. We begin with an initial $S_{H}$ distribution generated with the full variance computed from the well log data, and then reduce the variance by factors of 8 and 64 to reduce heterogeneity and approach the homogeneous Base Case conditions via multiple scenarios. Note that the overall structure/distribution of the heterogeneity is identical for each sub-Case, with only the magnitude of the variance (and hence the range of $S_{H}$ ) changing between sub-Cases. Therefore, the kind of heterogeneity is similar in all three sub-Cases, with the distinction existing in the magnitude of the variations.

In Figure 3, we compare the various Case 4 scenarios to the Base Case. Case $4 \mathrm{a}$ and $4 \mathrm{~b}$, the two scenarios with the largest variances, exhibit similar behavior with respect to $Q_{P}$ vs. $t$. The initial rate of production is similar to the Base Case for both $4 \mathrm{a}$ and $4 \mathrm{~b}$, but this low production rate, around $Q_{P}=0.0053 \mathrm{ST} \mathrm{m}^{3} / \mathrm{s}(0.016 \mathrm{MMSCFD})$, is maintained for the full $7 \mathrm{yr}$ simulation time with no increase in production. For much of this simulation time, the $\mathrm{pT}+\mathrm{H}$ solvers required very small timesteps (consuming a great deal of computer time), a sign that the system was experiencing very sharp fronts and steep gradients. Neither Case $4 \mathrm{a}$ or $4 \mathrm{~b}$ exhibits the rapid growth in production seen in the Base Case, or in Cases $3 \mathrm{a}$ and $3 \mathrm{~b}$. Cumulative production, in Figure 4, shows little difference between Case 4a and 4b, and the water-to-gas ratio, in Figure 5, is second only to Case 2a in high relative water production. Only reducing the variance by a factor of 64 , as in Case 4c, improves the rate of production in any noticeable way. For Case 4c, in Figure 3, we see that $Q_{P}$ begins to climb after about 300 days of production, following the path of the Base Case. However, by $t=450 \mathrm{~d}$, the $Q_{P}$ drops suddenly and levels off, paralleling the poor production profiles of Cases $4 \mathrm{a}$ and $4 \mathrm{~b}$. This is reflected in the cumulative production volumes seen in Figure 4 , where $V_{P}$ for Case $4 \mathrm{c}$ separates from Cases $4 \mathrm{a}$ and $4 \mathrm{~b}$ around 300 days, but fails to gain any significant advantage over time. However, Case $4 \mathrm{c}$ does gain a mild advantage in $R_{W G C}$, particularly after $t=300 \mathrm{~d}$.

Case 5: Geostatistical porosity. The representation of heterogeneity in intrinsic porous media properties is particularly difficult. Heterogeneity likely exists down to the pore scale, and the assumptions of Darcy's law stipulate that the porous media can be treated as a continuum that gains a single set of intrinsic properties from the various small-scale interactions and structures within. For Case 5, we vary porosity locally in order to examine the possibility of localized effects as well as any variations in flow and transport due to heterogeneous media properties.

Figure 6 compares Case 1, the Base Case, with Case 5a and 5b. Note immediately that for Case 5b, where the variance of the porosity is curtailed (to bring the range to within approximately 0.38 to 0.42 at $\sigma^{2}=0.011 / 64$, which is closer to th estimated porosity variation for the unit-D HBL), the $Q_{R}$ and $Q_{P}$ are essentially identical to those of the Base Case, and this small range of porosities does not affect either the rate of hydrate dissociation nor affect transport of gas to the well for production. Case 5a (with a range truncated to $0.10-0.70$ at $\sigma^{2}=0.030$ ), however, shows a marked leveling off of both $Q_{R}$ and $Q_{P}$ at approximately $t=1 \mathrm{yr}$, and the system never recovers. By $t=5.6 \mathrm{yr}$, the simulation experiences profound numerical challenges represented by reduced timesteps and increases in computational time, suggesting complex behavior at small length and time scales, and the simulation is stopped after production shows a steady downward trend.

\section{Results: Evolution of Spatial Distributions}

In this section, we present selected diagrams of the evolution of system properties to illustrate the production behavior described in the previous section.

Case 1: Base Case. As stated in the previous section, the comprehensive analysis of Moridis et al. (2010) will not be repeated here.

Case 2: Uniform Distribution. Figure 7 presents the evolution of $S_{H}$ and $S_{G}$ for Case 2a. Several features are apparent. The distribution of hydrate at early times ranges from saturations, $S_{H}$, from about 0.40 to as high as 0.80 . These high saturations result in localized regions of low effective permeability, and the uncorrelated generation of the initial condition results in $S_{H}$ variations at very small length scales, and more significantly, length scales that correlate with the discretization of the mesh and not with any actual HBL property. Dissociation over nearly 4,000 days is limited to a few meters around the well, with little evidence of hydrate beyond $x=15 \mathrm{~m}$ being affected by the depressurization. The dissociation front is irregular, and we see the formation of structure at the length scale of the mesh discretization, as well as small patches of remaining hydrate in the dissociated zone. The gas saturation, $S_{G}$, remains low except for a small "bubble" of gas near the top of the deposit 
several meters from the well. No upper dissociation interface-a key feature in production from confined hydrates of all Classes - appears in the timeline. The evolution of $S_{H}$ and $S_{G}$ in Case $3 \mathrm{~b}$ is not significantly different. Although these configurations of $S_{H, 0}$ are unrealistic, it illustrates the consequences of a "worst case" scenario.

Case 3: Layering. In comparison, Cases $3 \mathrm{a}$ and $3 \mathrm{~b}$ yielded the higher $Q_{P}$ and $V_{P}$ of any scenario. Figure 8 illustrates the evolution of $S_{H}$ for these Cases. In both the isotropic and anisotropic $k$ scenarios, we see the stratification of the initial saturation distribution at early times. As production progresses, both Cases show widespread hydrate dissociation, both horizontally along the top of the deposit and in horizontal zones further below the well. The isotropic case, 3a, shows a greater degree of dissociation (lower $S_{H}$ ) at intermediate and long times, and at $t=50 \mathrm{yr}$, also exhibits the formation of a second horizontal hydrate-free channel at $z=-36.5 \mathrm{~m}$. The extensive dissociation, coupled with increases in $k_{\text {eff }}$ along these horizontal low- $S_{H}$ features, allows gas to move from deep within the deposit to the hydrate-free zone around the well. Figure 9 shows the evolution of $S_{G}$ for Cases 3a and 3b. For both Cases, we see the formation of an upper "bubble" of free gas at high saturations along the bottom of the overburden, and this gas is free to move toward the well after about 1 yr of production and dissociation. This is analogous to the behavior seen in the Base Case, where an upper dissociation interface forms and gas accumulates under the overburden and is readily available for production. In Cases $3 \mathrm{a}$ and $3 \mathrm{~b}$, the region of high $S_{G}$ is larger and appears at earlier times. Case 3a also shows accumulation of gas at $z=-38.8 \mathrm{~m}$ at $t=50 \mathrm{yr}$, just underneath a region of high $S_{H}$ (and low $k_{e f f}$ ). However, although the two Cases show different distributions of hydrate dissociation (due to reduced $k_{z}$ for the second Case), dissociation is still able to proceed efficiently along the top of the deposit, providing ample gas to produce, as seen in the $Q_{P}$ vs. $t$ plots. However, the lower $R_{W G C}$ of Case $3 \mathrm{~b}$ can be explained through 1) increased dissociation, flow, and transport in the horizontal direction, where gas accumulations along the top of the deposit, and 2) due to decreased vertical permeability, restricting flow of water from the lower reaches of the deposit.

Case 4: Geostatistical saturation. As generated, the spatially correlated random fields used to create the initial distributions of $S_{H}$ in Case 4 are similar in structure, with only the variance (and hence, the width of the saturation distribution) varying from Case 4a through Case 4c. Again, the kind of heterogeneity is similar in all three sub-Cases, with the distinction existing in the magnitude of the variations. This allows an interesting comparison of small-scale features within the evolving hydrate deposit at different levels of heterogeneity.

Figure 10 presents the evolution of hydrate saturation vs. time for the three scenarios, $4 \mathrm{a}, 4 \mathrm{~b}$, and $4 \mathrm{c}$. The pattern of dissociation for all three sub-Cases is similar at early times - the initial dissociation occurs horizontally out from the well, then penetrates downward following a region of relatively lower $S_{H}$, with this zone of somewhat higher $k_{\text {eff }}$ communicating the depressurization deeper into the deposit. Other common features of all three sub-Cases are 1) an increase in hydrate saturation at the top of the deposit in the vicinity of $x=6 \mathrm{~m}-12 \mathrm{~m}$, and 2) an increase in stratification and local $S_{H}$ heterogeneity within $20 \mathrm{~m}$ of the well, in a form often referred to as "wormholes" or "hydrate lensing" (Moridis et al., 2008a). Such structures are not observed in the Base Case, which dissociates in a smooth and orderly fashion. One notable observation is that while cases $4 \mathrm{a}$ and $4 \mathrm{c}$ are very different at early times in terms of the range of hydrate saturations, but $\mathrm{t}=$ $6.5 \mathrm{yr}$, both of this end Cases show significant secondary hydrate forming at the leading edge of the horizontal dissociation front, which would be expected to lead to lowered $k_{\text {eff }}$ in both cases for gas that attempt to flow along the top of the deposit toward the well.

In all sub-Cases, however, gas formation, seen in Figure 11, is restricted to limited zones near the top of the deposit in front of the horizontal dissociation front, and for Case $4 \mathrm{a}$, also in some limited zones of lower $S_{H}$ near the bottom of the underburden. The lowest saturations are found in Case $4 \mathrm{~b}$, with intermediate geostatistical $S_{H}$ variance. However, the evolution of $S_{G}$ seen here correlates with the poor performance of the deposit in terms of production, as seen in Figure 3 and 4 , and also the similar (and poor) $R_{W G C}$ ratios seen in Figure 5.

Tracking pressure, $P$, over time, provides the best example of the consequences of heterogeneity in a complex, multiphase system. The evolution of $\mathrm{P}$ for Cases $4 \mathrm{~b}$ and $4 \mathrm{c}$ show nothing usual in comparison to previous studies-for example, the Base Case (Moridis et al., 2010). However, Case $4 \mathrm{a}$, with the greatest range of initial $S_{H, 0}$, shows markedly different behavior, seen in Figure 12 (note that the horizontal scale now encompasses the full width of the deposit, and the vertical scale includes $1 \mathrm{~m}$ each of the overburden and underburden). We see the pressure drop at the well propagate outward and horizontally through the deposit as production advances, but many regions of the deposit remain at roughly their initial $P_{0}$. These are regions of high $S_{H, 0}$ that have (or are surrounded by regions with) no effective permeability, and as such do not dissociate, dissociate too slowly to contribute to production, or will only dissociate if thermal stimulation is applied on a large scale. Also, notice that, at early times, we see steep transitions between zones of varying pressures - at $x=35 \mathrm{~m}, 105 \mathrm{~m}$, and $130 \mathrm{~m}$. In these transitions, it appears that the impermeable zones restriction flow to "channels" of higher $k_{\text {eff. }}$ On a smaller scale (for example, near the wellbore), this sort of flow channeling often leads to secondary hydrate formation, the creating of "wormholes" (Moridis et al., 2008a) or migrating barriers of solid hydrate (Moridis and Reagan, 2007a).

Case 5: Geostatistical porosity. As stated in the previous section, we vary porosity locally without modifying other (likely 
correlated) properties in order to examine the possibility of localized thermodynamic effects, variations in flow and transport due to heterogeneous media properties, and to isolate the effects of a single reservoir property. Homogeneous intrinsic permeability and homogeneous $S_{H}$ are used for Case 5 initial conditions.

While small variations in porosity (Case $5 b$ ) had no significant effect on hydrate dissociation or production, the effect of the full variance (Case 5a) resulted in severe reductions in $Q_{P}$ and $Q_{R}$ after $t=1 \mathrm{yr}$ (Figure 6). Figure 13 compares the evolution of $S_{H}$ for the Base Case vs. Case $5 \mathrm{a}$ at two points along production. The first comparison, at $t=1 \mathrm{yr}$, shows a similar configuration of hydrate and a similar degree of hydrate dissociation, and this is consistent with the similar $Q_{P}$ and $Q_{R}$ curves for the two Cases up to $t=1 \mathrm{yr}$. Beyond year one, however, $Q_{P}$ an $Q_{R}$ diverge, and the second row of Figure 13 shows the state of the two systems at about $t=3 \mathrm{yr}$. While the Base Case clearly shows the beginning of the formation of an upper dissociation interface (common to hydrate production in Class 1, 2, and 3 hydrates) (Moridis and Reagan, 2007b; Moridis et al., 2008a) Case 5a shows significant formation of secondary hydrate at the top of the HBL at $x>8 \mathrm{~m}$, which is impeding the typical progress of dissociation along the bottom of the overburden and the formation of a bubble of free gas along the top of the HBL. Instead, dissociation in Case 5a is following a region of slightly decreased porosity downward and away from the overburden, and both significant secondary hydrate formation as well as "hydrate lensing" are already apparent.

\section{Conclusions}

This study is part of an effort led by the U.S. Department of Energy to identify appropriate targets for a long-term field test of production from permafrost-associated hydrate deposits. We focused on the evaluation of the gas production potential of the unit D hydrate accumulation at the Mount Elbert site, North Slope, Alaska, and investigated the performance of horizontal wells and depressurization-induced dissociation under several scenarios of deposit heterogeneity. The results suggest the following conclusions:

1) Heterogeneity in initial conditions may have a significant effect on the evolution of production over time, and play a large role in whether a deposit is technically and economically feasible as a production target.

2) Layered systems, represented both through permeability anisotropy and through horizontal zones of different hydrate saturation, can enhance a deposit's ability to produce gas, increasing both the rate of dissociation, $Q_{R}$, and the rate of gas produced at the well, $Q_{P}$, by creating channels of higher $k_{\text {eff. }}$. These channels enhance dissociation by propagating the effects of depressurization more effectively, and enhance production by offering high-permeability pathways for the migration of gas from within the dissociating HBL to the well.

3) Even minor heterogeneity in the initial hydrate saturation, when considered alone, can result in significant difficulties in both dissociating hydrate via depressurization and removing the resulting methane via a horizontal well. The initial variations in $S_{H, 0}$ lead to initial variations in $k_{\text {eff }}$ that lead to nonuniform dissociation, non-smooth dissociation fronts, selective flow channeling, and eventually the formation of secondary hydrate in a self-reinforcing process, similar to the "moving solid barriers" and "hydrate lensing" seen in previous simulations of production (Moridis et al., 2008a; Moridis and Reagan, 2007a). In Cases 2 though 4, each production attempt with heterogeneous $S_{H, 0}$ resulted in secondary hydrate formation near the top of the deposit, stopping the formation of the typical (and necessary) upper dissociation interface that typically feeds large quantities of gas to the well.

4) Production is less sensitive to heterogeneous porosity, $\phi$, despite earlier studies (Reagan and Moridis, 2008) that suggest significant sensible-heat effects from the changes in porosity. Much larger variances are required to create production difficulties, but the overall effect is similar to what is seen in Cases 2-4: secondary hydrate formation self-reinforced by flow channeling and the elimination of the upper dissociation interface, resulting in poor production performance.

The results also indicate that more work needs to be done to study these effects, including:

1) The effective of heterogeneity in other parameters needs to be studied, including intrinsic permeability, but more importantly,

2) The effect of coupling between properties should be parameterized and examined for various heterogeneous cases. Realistic heterogeneous systems should have coupled porosity and permeability, and also coupled porosity and $S_{H, 0}$, reflecting the relationships between these variables during the formation of the deposit.

3) The simulation of heterogeneous systems must be expanded to three dimensions, without removing the fine discretization used in the 2-D cases. It is clear that flow channels through regions of higher $k_{\text {eff }}$ is a significant process, and in reality, moving fluids have a full three dimensions in which to find the path of least resistance through the HBL. Assumptions of uniformity along the third axis break down under heterogeneity, and full geostatistical realizations of the system (barring the existence of sufficient data to construct an actual 3-D distribution) are the only truly representative way to simulate the evolution of these complex systems. 


\section{Acknowledgment}

This work was supported by the Assistant Secretary for Fossil Energy, Office of Natural Gas and Petroleum Technology, through the National Energy Technology Laboratory, under the U.S. Department of Energy, Contract No. DE-AC02$05 \mathrm{CH} 11231$.

\section{Nomenclature}

$\Delta t=$ Timestep size $(\mathrm{s})$

$\Delta x=$ Discretization along the $x$ axis $(\mathrm{m})$

$\Delta z=$ Vertical discretization, i.e., in the $z$-direction (m)

$C=$ specific heat $(\mathrm{J} / \mathrm{kg} / \mathrm{K})$

$k=$ intrinsic permeability $\left(\mathrm{m}^{2}\right)$

$k_{\Theta}=$ thermal conductivity $(\mathrm{W} / \mathrm{m} / \mathrm{K})$

$k_{\Theta R D}=$ thermal conductivity of dry porous medium $(\mathrm{W} / \mathrm{m} / \mathrm{K})$

$k_{\Theta R W}=$ thermal conductivity of fully saturated porous medium $(\mathrm{W} / \mathrm{m} / \mathrm{K})$

$M_{W}=$ mass of water removed, cumulative $(\mathrm{kg})$

$N_{H}=$ hydration number

$P=$ pressure $(\mathrm{Pa})$

$P_{0}=$ initial pressure in hydrate-bearing sediments $(\mathrm{Pa})$

$P_{w}=$ constant well pressure $(\mathrm{Pa})$

$Q_{P}=$ volumetric rate of $\mathrm{CH}_{4}$ production at the well $(\mathrm{ST} \mathrm{m} / \mathrm{s})$

$Q_{R}=$ rate of $\mathrm{CH}_{4}$ release from hydrate dissociation $(\mathrm{ST} \mathrm{m} / \mathrm{s})$

$R_{W G C}=$ ratio of water removed to gas production, cumulative $\left(\mathrm{kg} / \mathrm{ST} \mathrm{m}{ }^{3}\right)$

$S=$ phase saturation

$t=$ time (days)

$T=$ temperature $\left({ }^{\circ} \mathrm{C}\right)$

$V_{R}=$ cumulative volume of $\mathrm{CH}_{4}$ released from hydrate dissociation $\left(\mathrm{ST} \mathrm{m}^{3}\right)$

$V_{P}=$ cumulative volume of $\mathrm{CH}_{4}$ released produced at the well $\left(\mathrm{ST} \mathrm{m}^{3}\right)$

$X=$ mass fraction $(\mathrm{kg} / \mathrm{kg})$

\section{Greek Symbols}

$\lambda=$ van Genuchten exponent

$\phi=$ porosity

\section{Subscripts and Superscripts}

$0=$ denotes initial state

$A=$ aqueous phase

$e=$ equilibrium conditions

cap $=$ capillary

$G=$ gas phase

$H=$ solid hydrate phase

$H, O=$ initial solid hydrate phase

$\operatorname{ir} G=$ irreducible gas

$i r A=$ irreducible aqueous phase

$n=$ permeability reduction exponent

$P=$ production stream

$R=$ rock

\section{References}

Anderson, B., Hancock, S., Wilson, S., Enger, C., Collett, T., Boswell, R., Hunter, R., 2010. Modular Formation Dynamics testing at the Mount Elbert-01 stratigraphic test well, Milne point unit, North Slope Alaska: Operational summary, history matching, and interpretation. Mar. Pet. Geo., doi:10.1016/j.marpetgeo.2010.02.012.

Boswell, R., Hunter, R., Collett, T.S., Digert, S., Hancock, S., Weeks, M., and Mount Elbert Science Team, 2008, Investigation of gas hydrate bearing sandstone reservoirs at the Mount Elbert stratigraphic test well, Milne Point, Alaska, Proc. of the 6th International Conference on Gas Hydrates, July 6-10, 2008, Vancouver, British Columbia, Canada.

Bird, K.J., and Magoon, L.B., 1987, Petroleum geology of the northern part of the Arctic National Wildlife Refuge, Northeastern Alaska. U.S. Geological Survey Bulletin 1778: 324.

Clarke, M.A., and Bishnoi, P.R., 2000. Determination of the Intrinsic Rate of Methane Gas Hydrate Decomposition, Chem. Eng. Sci., 55: 4869.

Collett, T.S., Bird, K.J., Kvenvolden, K.A., and Magoon, L.B., 1988, Geologic interrelations relative to gas hydrates within 
the North Slope of Alaska: U.S. Geological Survey Open-File Report 88-389, 150.

Collett, T., 1993, Natural gas hydrates of the Prudhoe Bay and Kuparuk River area, North Slope, Alaska: American Association of Petroleum Geologists Bulletin, 77 (5): 793-812.

Collett, T., 1995. 1995 National Assessment of U.S. Oil and Gas Resources (on CD-ROM) (Gautier, D.L., Goldton, G.L. et al., eds.), USGS.

Collett, T., 2007. Arctic Gas Hydrate Energy Assessment Studies, The Arctic Energy Summit, Anchorage, Alaska, 15-18 October 2007.

Dallimore, S.R., Uchida, T., and Collett, T.S., 1999, Scientific results from JAPEX/JNOC/GSC Mallik 2L-38 gas hydrate research well, Mackenzie Delta, Northwest Territories, Canada, Geological Survey of Canada Bulletin 544: 403.

Dallimore, S.R., and Collett, T.S., Eds., 2005. Scientific Results from the Mallik 2002 Gas Hydrate Production Research Well Program, Mackenzie Delta, Northwest Territories, Canada, Geological Survey of Canada Bulletin 585.

Deutsch, C. V., and A. G. Journel, 1992, GSLIB: Geostatistical Software Library and User's Guide, Oxford Univ. Press, New York.

Kim, H.C., Bishnoi, P.R., Heidemann, R.A., and Rizvi, S.S.H., 1987. Kinetics of Methane Hydrate Decomposition, Chem. Eng. Sci., 42(7): 1645.

Klauda, J.B., and Sandler, S.I., 2005. Global distribution of methane hydrate in ocean sediment, Energy \& Fuels 19: 469.

Kowalsky, M. B., and Moridis, G.J., 2007, Comparison of kinetic and equilibrium reactions in simulating the behavior of gas hydrates, Energy Conversion and Management, 48: 1850.

Kurihara, M., Sato, A., Ouchi, H., Narita, H., Masuda, Y., Saeki, T., and Fujii, T. 2009. Prediction of Gas Productivity from Eastern Nankai Trough Methane-Hydrate Reservoirs. SPE Res Eval \& Eng 12 (3): 477-499.

Milkov, A. V., 2004. Global estimates of hydrate-bound gas in marine sediments: How much is really out there? Earth Science Reviews 66 (3): 183.

Makogon, Y.F., 1987. Gas hydrates: frozen energy, Recherche 18 (192): 1192.

Makogon, Y.F., 1997. Hydrates of Hydrocarbons. Penn Well Publishing Co. Tulsa, OK.

Moridis, G.J., 2003. Numerical Studies of Gas Production From Methane Hydrates, SPE Journal, 32 (8): 359.

Moridis, G.J., and Sloan, E.D., 2007. Gas Production Potential of Disperse Low-Saturation Hydrate Accumulations in Oceanic Sediments, J. Energy Conversion and Management, 48 (6): 1834-1849.

Moridis, G.J., Collett, T., Dallimore, S., Satoh, T., Hancock, S., and Weatherhill, B., 2004. Numerical Studies Of Gas Production From Several Methane Hydrate Zones At The Mallik Site, Mackenzie Delta, Canada, J. Pet. Sci. Eng. 43: 219.

Moridis, G.J. and Reagan, M.T., 2007a. Strategies for Gas Production From Oceanic Class 3 Hydrate Accumulations, OTC18865, Proc. 2007 Offshore Technology Conference, Houston, Texas, 30 April - 3 May 2007.

Moridis, G.J. and Reagan, M.T., 2007b. Gas Production From Oceanic Class 2 Hydrate Accumulations, OTC 18866, Proc. 2007 Offshore Technology Conference, Houston, Texas, U.S.A., 30 April-3 May 2007.

Moridis, G.J. and Reagan, M.T., Gas Production From Class 2 Hydrate Accumulations in the Permafrost, 1. System Description and Base Production Case" J. Pet. Sci. Eng., in press, 2010.

Moridis, G.J., Collett, T.S., Boswell, R., Kurihara, M., Reagan, M.T., Koh, C., Sloan, E.D., 2009. Toward Production from Gas Hydrates: Status, Technology, and Potential, SPE 114163, SPE Journal, 12 (5): 745-771.

Moridis, G.J., Kowalsky, M., and Pruess, K., 2008a. Depressurization-Induced Gas Production From Class 1 Hydrate Deposits, SPE Reservoir Evaluation and Engineering, 10 (5): 458-488.

Moridis, G.J., Kowalsky, M.B., and Pruess, K., 2008b. TOUGH+HYDRATE v1.0 User's Manual: A Code for the Simulation of System Behavior in Hydrate-Bearing Geologic Media, Report LBNL-00149E, Lawrence Berkeley National Laboratory, Berkeley, CA.

Moridis, G.J., Silpngarmlert, S., Reagan, M.T., Collett, T., and K. Zhang, 2010. Gas Production From a Cold, Stratigraphically Bounded Hydrate Deposit at the Mount Elbert Site, North Slope, Alaska, Marine \& Petroleum Geology, doi: 10.1016/j.marpetgeo.2010.01.005.

Reagan, M.T., Moridis, G.J., and Zhang, K., 2008. Sensitivity Analysis of Gas Production from Class 2 and Class 3 Hydrate Deposits, OTC 19554, Proc. 2008 Offshore Technology Conference, Houston, Texas, USA, 5-8 May 2008.

Sloan, E.D., and Koh, C., 2008. Clathrate Hydrates of Natural Gases. 3rd Edition, Taylor and Francis, Inc., Boca Raton, FL.

Sun, X., and Mohanty, K.K., 2005. Simulation of Methane Hydrate Reservoirs, SPE 93015, Proc, 2005 SPE Reservoir Simulation Symposium, Houston, TX U.S.A., 31 January - 2 February 2005.

van Genuchten, M.Th., 1980. A Closed-Form Equation for Predicting the Hydraulic Conductivity of Unsaturated Soils", Soil Sci. Soc. 44: 892.

Wright, J.F., Dallimore, S.R., and Nixon, F.M., 1999. Influences of Grain Size and Salinity on Pressure-Temperature Thresholds for Methane Hydrate Stability in JAPEX/JNOC/GSC Mallik 2L-38 Gas Hydrate Research-Well Sediments, in Scientific Results from JAPEX/JNOC/GSC Mallik 2L-38 Gas Hydrate Research-Well, Mackenzie Delta, Northwest Territories, Canada. Dallimore, S.R., Uchida, T., and Collett, T.S., Eds., Geological Survey of Canada Bulletin 544: 229.

Zhang, K., and Moridis, G.J., 2008. A Domain Decomposition Approach for Large-Scale Simulations of Coupled Processes in Hydrate-Bearing Geologic Media, Proc. 6th International Conference on Gas Hydrates, Vancouver, British Columbia, Canada, July 6-10, 2008. 


\begin{tabular}{|c|c|}
\hline Parameter & Value \\
\hline Hydrate zone thickness & $11.3 \mathrm{~m}$ \\
\hline Initial pressure at top of $\mathrm{HBL}\left(P_{T}\right)$ & $6.386 \mathrm{MPa}$ \\
\hline Initial temperature at top of $\mathrm{HBL}\left(T_{T}\right)$ & $2.3^{\circ} \mathrm{C}$ \\
\hline Initial temperature at base of $\mathrm{HBL}\left(T_{B}\right)$ & $2.6^{\circ} \mathrm{C}$ \\
\hline Gas composition & $100 \% \mathrm{CH}_{4}$ \\
\hline Initial saturations in the $\mathrm{HBL}$ & $S_{H}=0.65, S_{A}=0.35$ \\
\hline Intrinsic permeability of $\mathrm{HBL} k_{x}=k_{z}$ & $10^{-12} \mathrm{~m}^{2}(=1 \mathrm{D})$ \\
\hline Porosity of HBL $\phi$ & 0.4 \\
\hline Compressibility of HBL & $5 \times 10^{-9} \mathrm{~Pa}^{-1}$ \\
\hline $\begin{array}{l}\text { Intrinsic permeability } k_{x}=k_{z} \\
\text { (overburden \& underburden) }\end{array}$ & $0 \mathrm{~m}^{2}(=0 \mathrm{D})$ \\
\hline Porosity of overburden \& underburden & 0.005 \\
\hline Grain density $\rho_{R}$ (all formations) & $2750 \mathrm{~kg} / \mathrm{m}^{3}$ \\
\hline Constant bottomhole pressure $\left(P_{w}\right)$ & $3 \mathrm{MPa}$ \\
\hline $\begin{array}{l}\text { Dry thermal conductivity }\left(k_{\Theta R D}\right) \\
\text { (all formations) }\end{array}$ & $0.5 \mathrm{~W} / \mathrm{m} / \mathrm{K}$ \\
\hline $\begin{array}{l}\text { Wet thermal conductivity }\left(k_{\Theta R W}\right) \\
\text { (all formations) }\end{array}$ & $3.1 \mathrm{~W} / \mathrm{m} / \mathrm{K}$ \\
\hline $\begin{array}{l}\text { Composite thermal conductivity } \\
\text { model (Moridis et al., 2008b) }\end{array}$ & $\begin{array}{l}k_{\Theta C}=k_{\Theta R D} \\
+\left(S_{A}^{1 / 2}+S_{H}^{1 / 2}\right)\left(k_{\Theta R W}-k_{\Theta R D}\right)+\phi S_{1} k_{\Theta l}\end{array}$ \\
\hline $\begin{array}{l}\text { Capillary pressure model } \\
\text { (van Genuchten, 1980) }\end{array}$ & $\begin{array}{l}P_{c a p}=-P_{0}\left[\left(S^{*}\right)^{-1 / \lambda}-1\right]^{\lambda} \\
S^{*}=\frac{\left(S_{A}-S_{i r A}\right)}{\left(S_{m \times A}-S_{i r A}\right)}\end{array}$ \\
\hline$S_{\text {irA }}$ & 1 \\
\hline$\lambda$ (White, 2008) & 0.77437 \\
\hline$P_{0}$ (White, 2008) & $5 \times 10^{3} \mathrm{~Pa}$ \\
\hline $\begin{array}{l}\text { Relative permeability model } \\
\text { (Moridis et al., 2008b) }\end{array}$ & $\begin{array}{l}k_{r A}=\left(S_{A}^{*}\right)^{n} \\
k_{r G}=\left(S_{G}^{*}\right)^{m} \\
S_{A}^{*}=\left(S_{A}-S_{i r A}\right) /\left(1-S_{i r A}\right) \\
S_{G}{ }^{*}=\left(S_{G}-S_{i r G}\right) /\left(1-S_{i r A}\right) \\
\text { EPM model }\end{array}$ \\
\hline$n ; m$ (from Anderson et al., 2010) & $4.2 ; 2.5$ \\
\hline$S_{i r G}$ & 0.02 \\
\hline$S_{i r A}$ & 0.20 \\
\hline
\end{tabular}




\begin{tabular}{lllll} 
Scenario & Var & Type & Properties & \\
\hline Case 1: & $\ldots$ & Base case & & \\
Case 2a: & $S_{H}$ & Uniform dist. & Isotropic $\left(k_{z}=k_{x}\right)$ & \\
Case 2b: & $S_{H}$ & Uniform dist. & Anisotropic $\left(k_{z}=0.1 k_{x}\right)$. & \\
Case 3a: & $S_{H}$ & Layered & Isotropic $\left(k_{z}=k_{x}\right)$ & \\
Case 3b: & $S_{H}$ & Layered & Anisotropic $\left(k_{z}=0.1 k_{x}\right)$. & \\
Case 4a: & $S_{H}$ & Geostatistical & mean $=0.65, \sigma^{2}=0.011$ & length scale $=0.95 \mathrm{~m}$, anisotropy $=10$ \\
Case 4b: & $S_{H}$ & Geostatistical & mean $=0.65, \sigma^{2}=\sigma^{2} / 8$ & length scale $=0.95 \mathrm{~m}$, anisotropy $=10$ \\
Case 4c: & $S_{H}$ & Geostatistical & mean $=0.65, \sigma^{2}=\sigma^{2} / 64$ & length scale $=0.95 \mathrm{~m}$, anisotropy $=10$ \\
Case 5a: & $\phi$ & Geostatistical & mean $=0.40, \sigma^{2}=0.030$ & length scale $=0.44 \mathrm{~m}$, anisotropy $=10$ \\
Case 5b: & $\phi$ & Geostatistical & mean $=0.40, \sigma^{2}=\sigma^{2} / 64$ & length scale $=0.44 \mathrm{~m}$, anisotropy $=10$ \\
& & & & \\
\hline
\end{tabular}

Table 2: Overview of the simulated heterogeneity scenarios. 


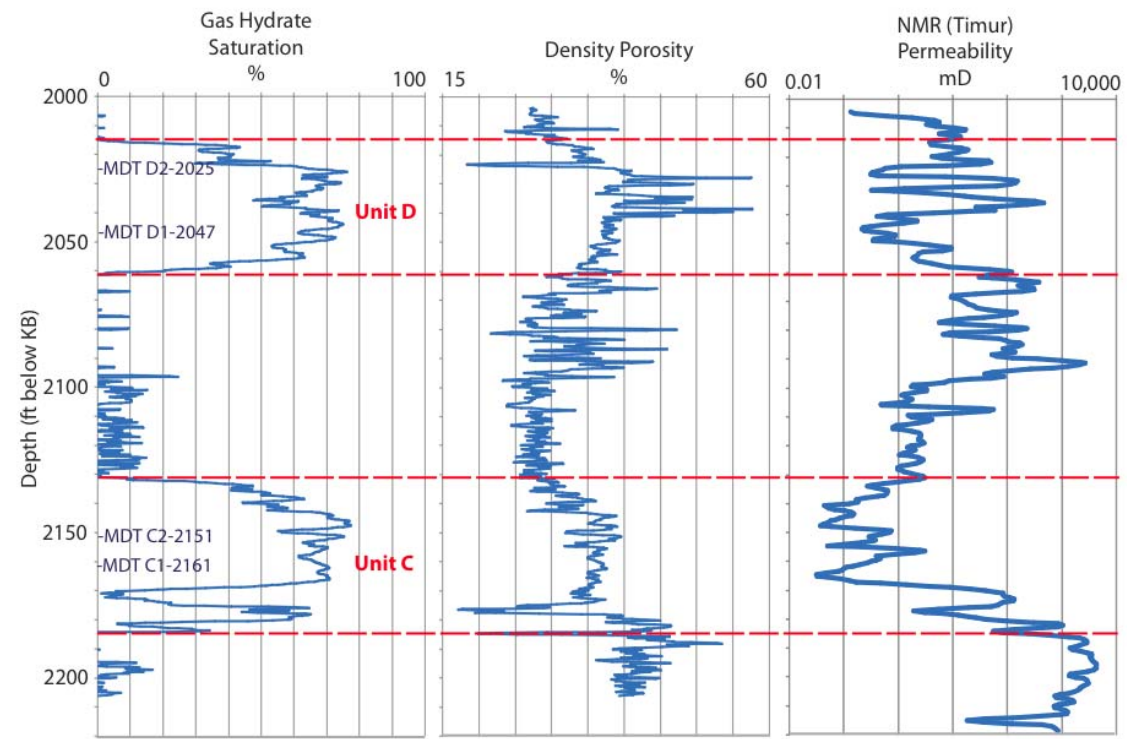

Figure 1. The $\mathrm{C}$ and $\mathrm{D}$ units at the Mount Elbert-01 location. The locations of the MDT tests in the two units are shown. 


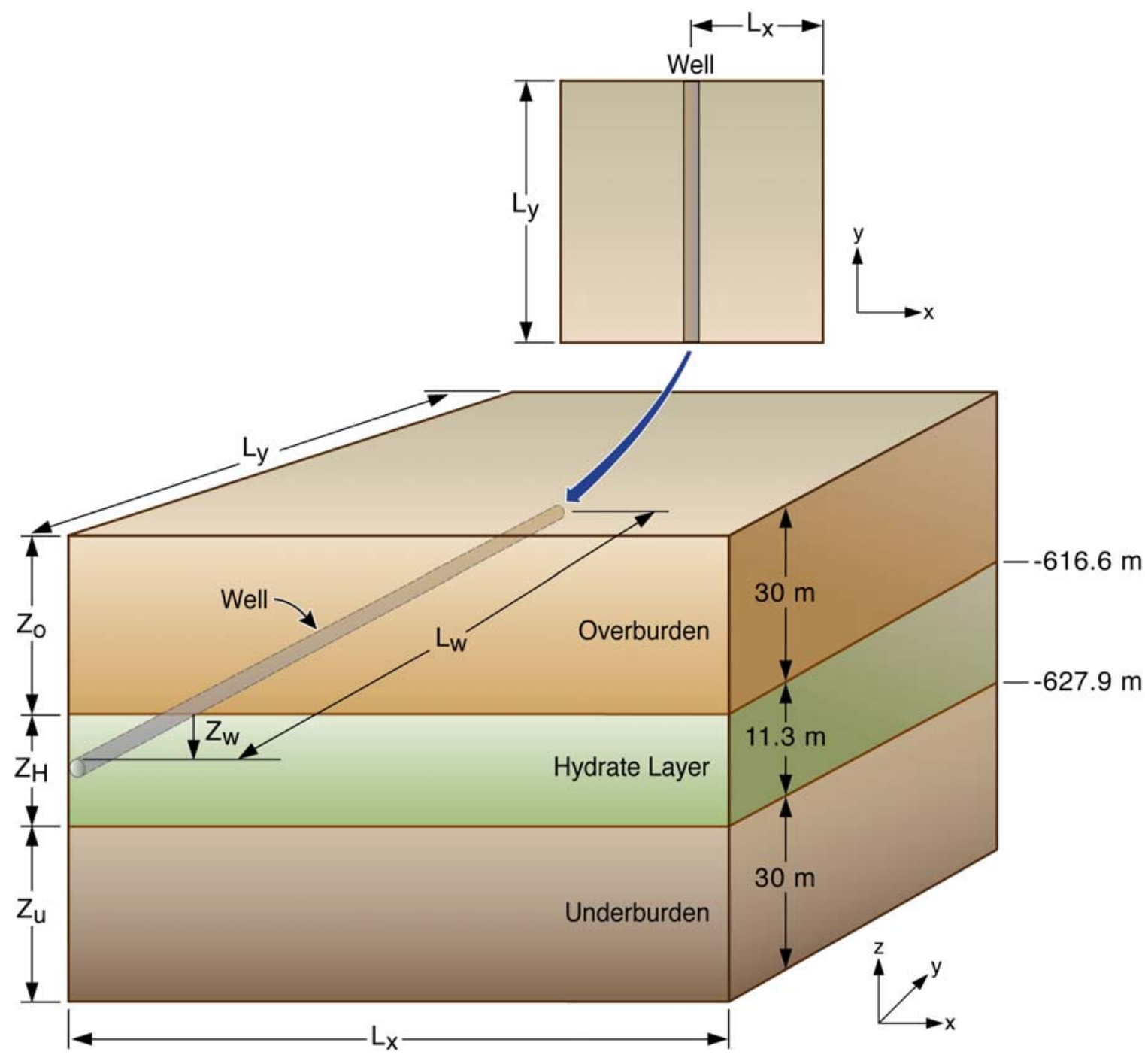

ESD09-012

Figure 2. System geometry and configuration of the horizontal well producing from a rectangular section of the Unit D hydrate deposit. Note that $L_{w}=L_{y}=709 \mathrm{~m}, L_{x}=L_{y} / 2=354.5 \mathrm{~m}, Z_{w}=0 \mathrm{~m}$. 


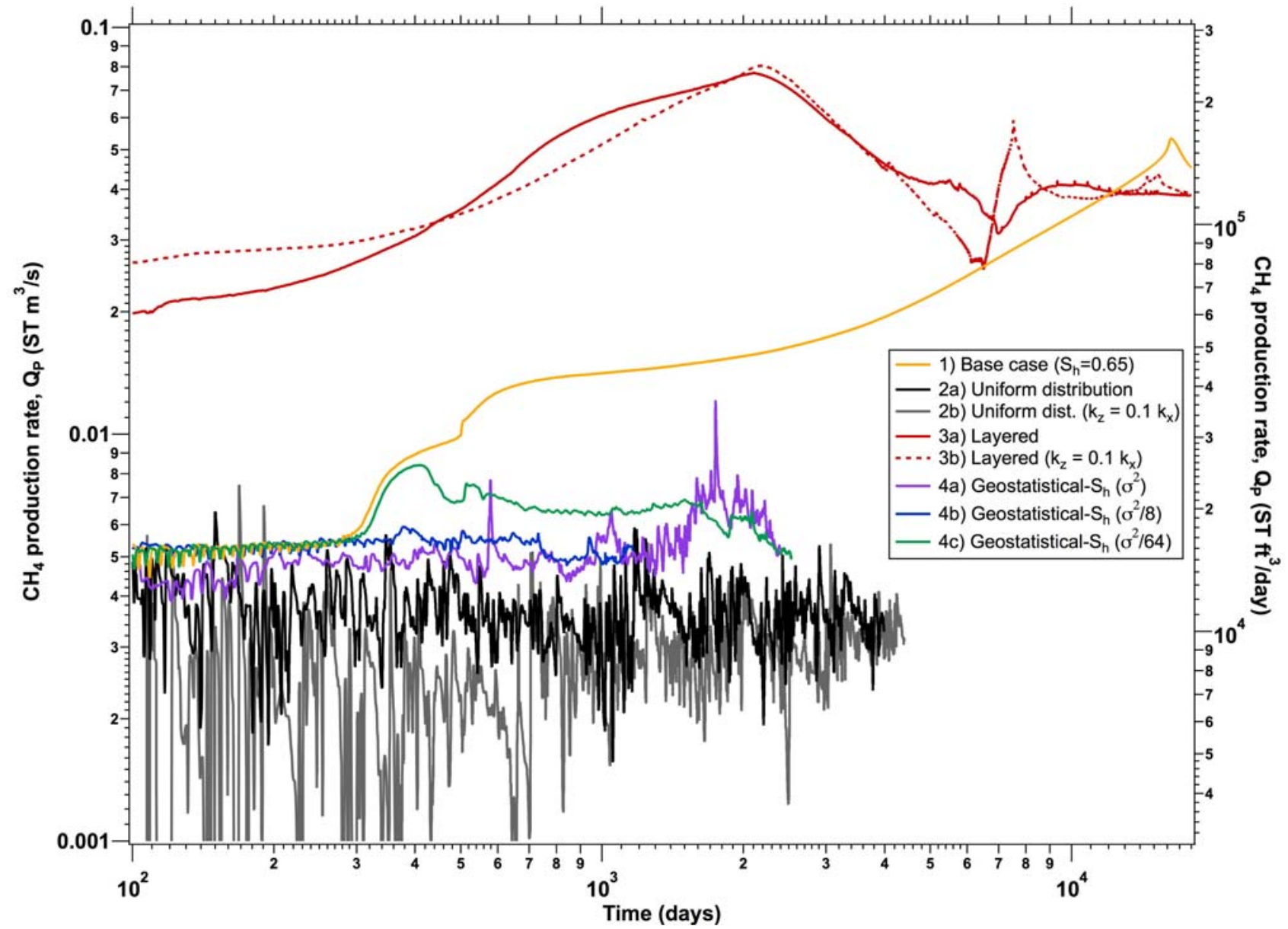

Figure 3. $\mathrm{CH}_{4}$ production at the well, $Q_{P}$, as simulated for the Base Case and $S_{H}$-heterogeneity scenarios 2 through 4. 


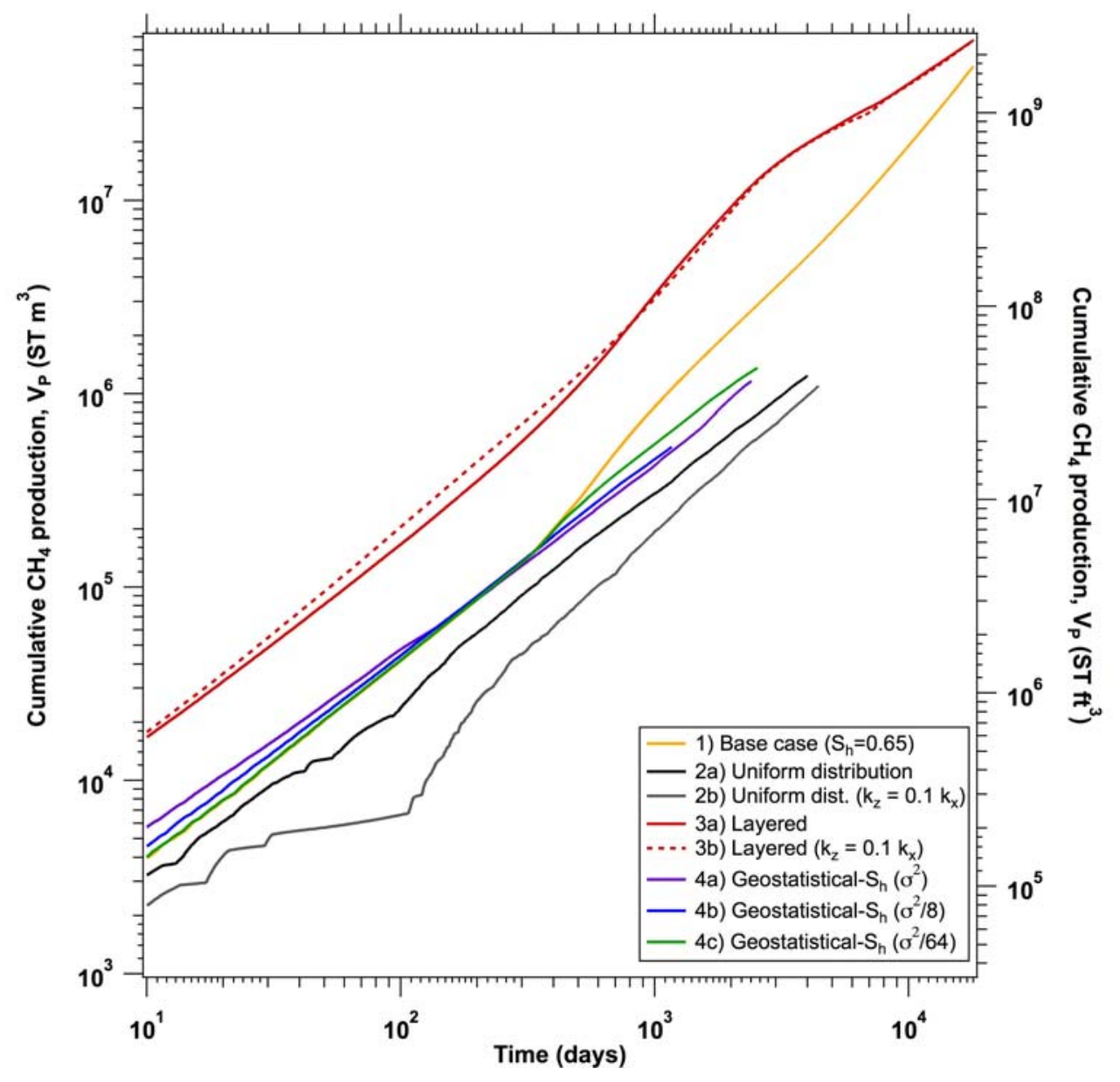

Figure 4. Cumulative $\mathrm{CH}_{4}$ produced at the well, $V_{P}$, as simulated for the Base Case and $S_{H}$-heterogeneity scenarios 2 through 4. 


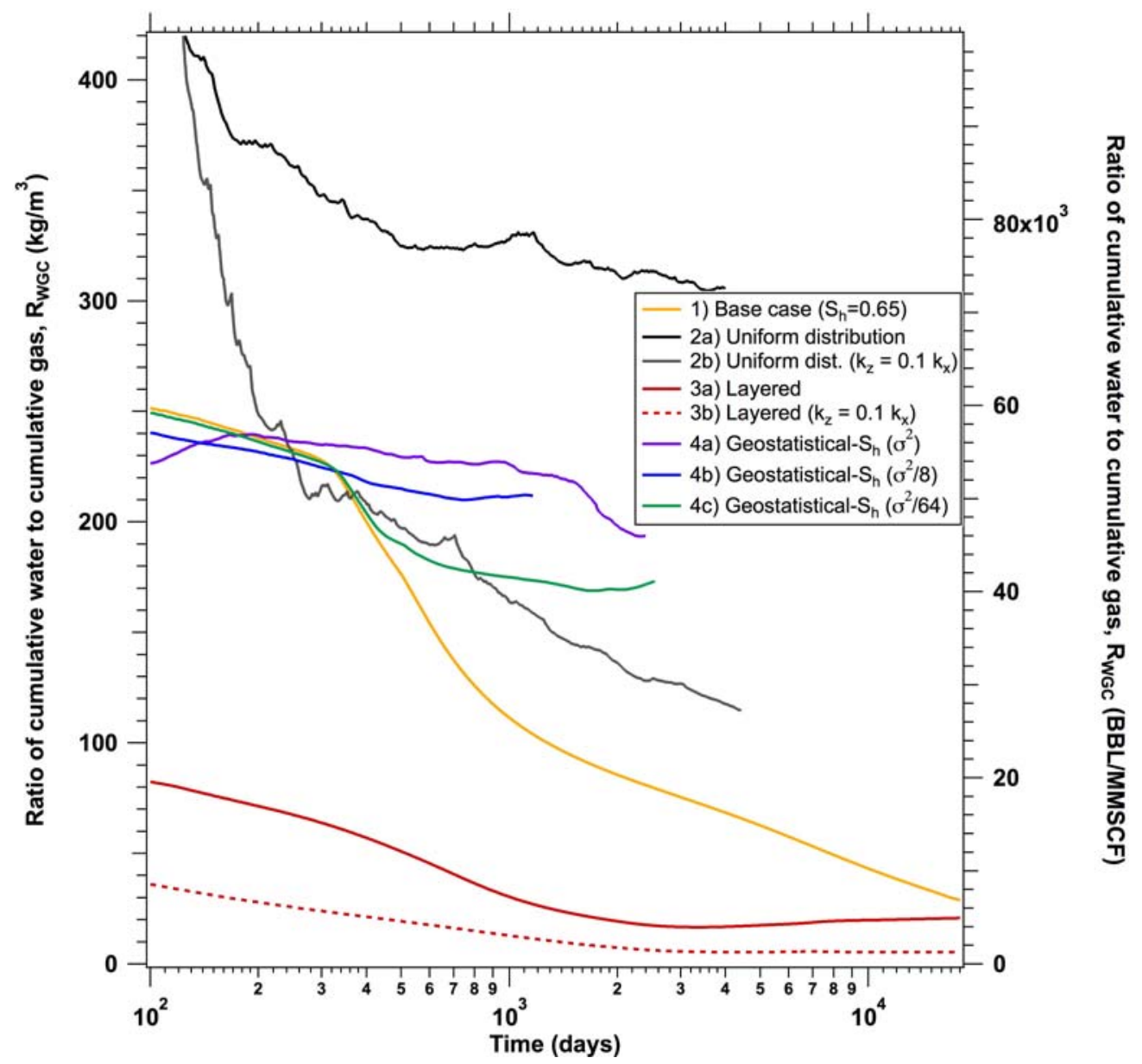

Figure 5. Ratio of cumulative water removed, $M_{W}$, to cumulative gas produced, $V_{P}, R_{W G C}=M_{W} / V_{P}$, for heterogeneity scenarios 1 through 4. 


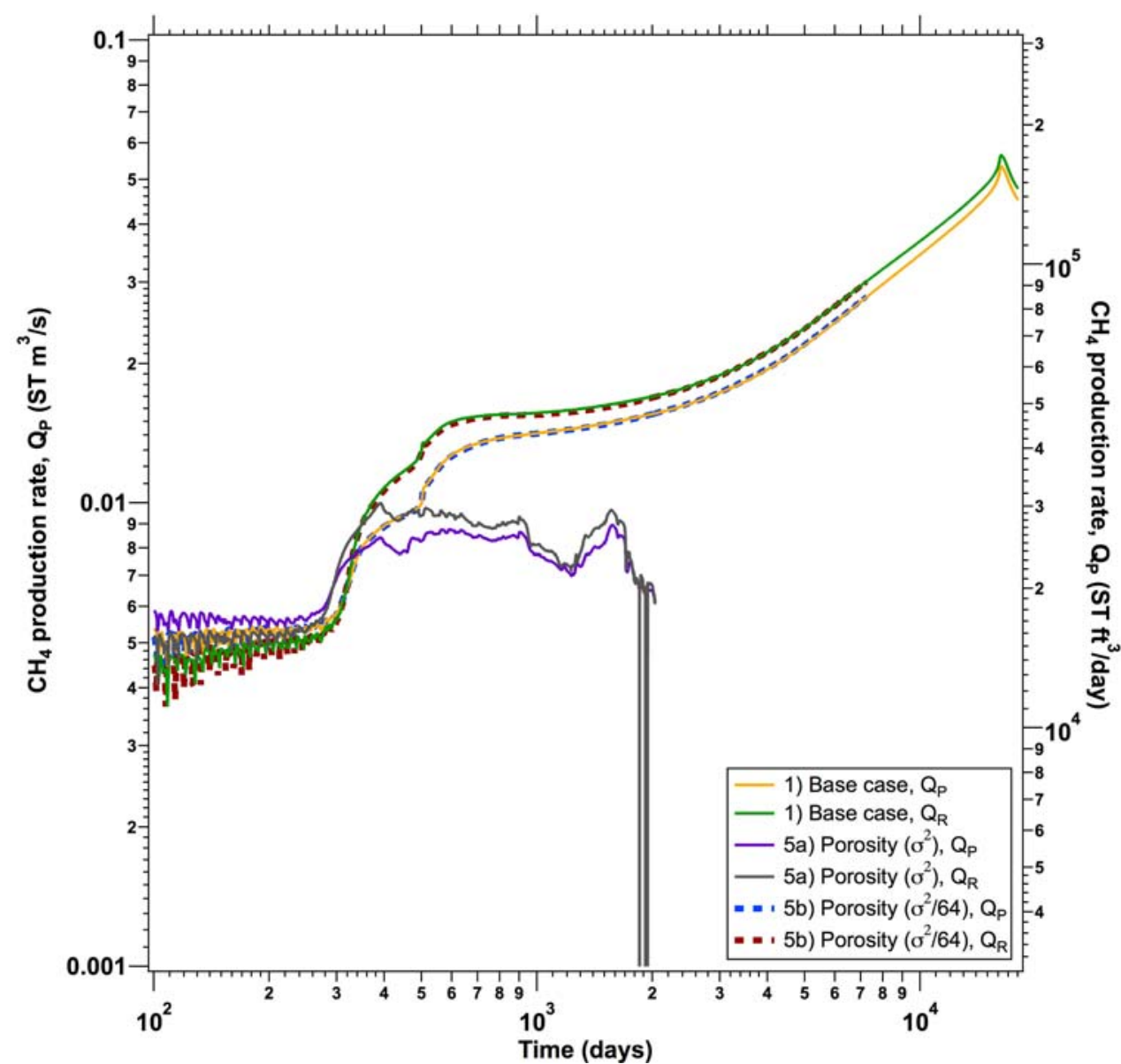

Figure 6. $\mathrm{CH}_{4}$ released via dissociation, $Q_{R}$, and $\mathrm{CH}_{4}$ production at the well, $Q_{P}$, as simulated for the Base Case and heterogeneity scenario 5 . 

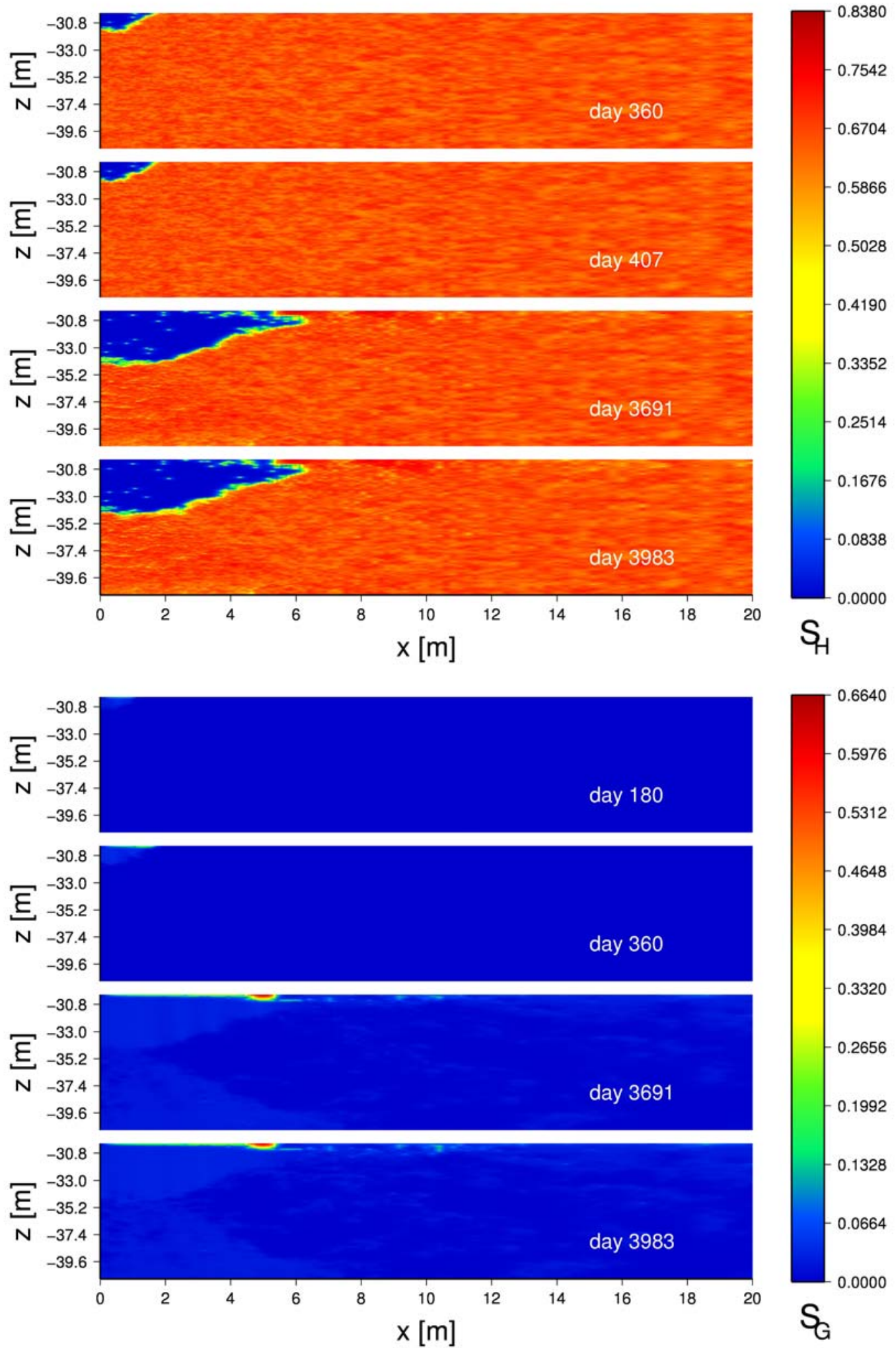

Figure 7. Evolution of hydrate saturation, $S_{H}$, vs. time and gas saturation, $S_{G}$, vs. time for Case 2a. 

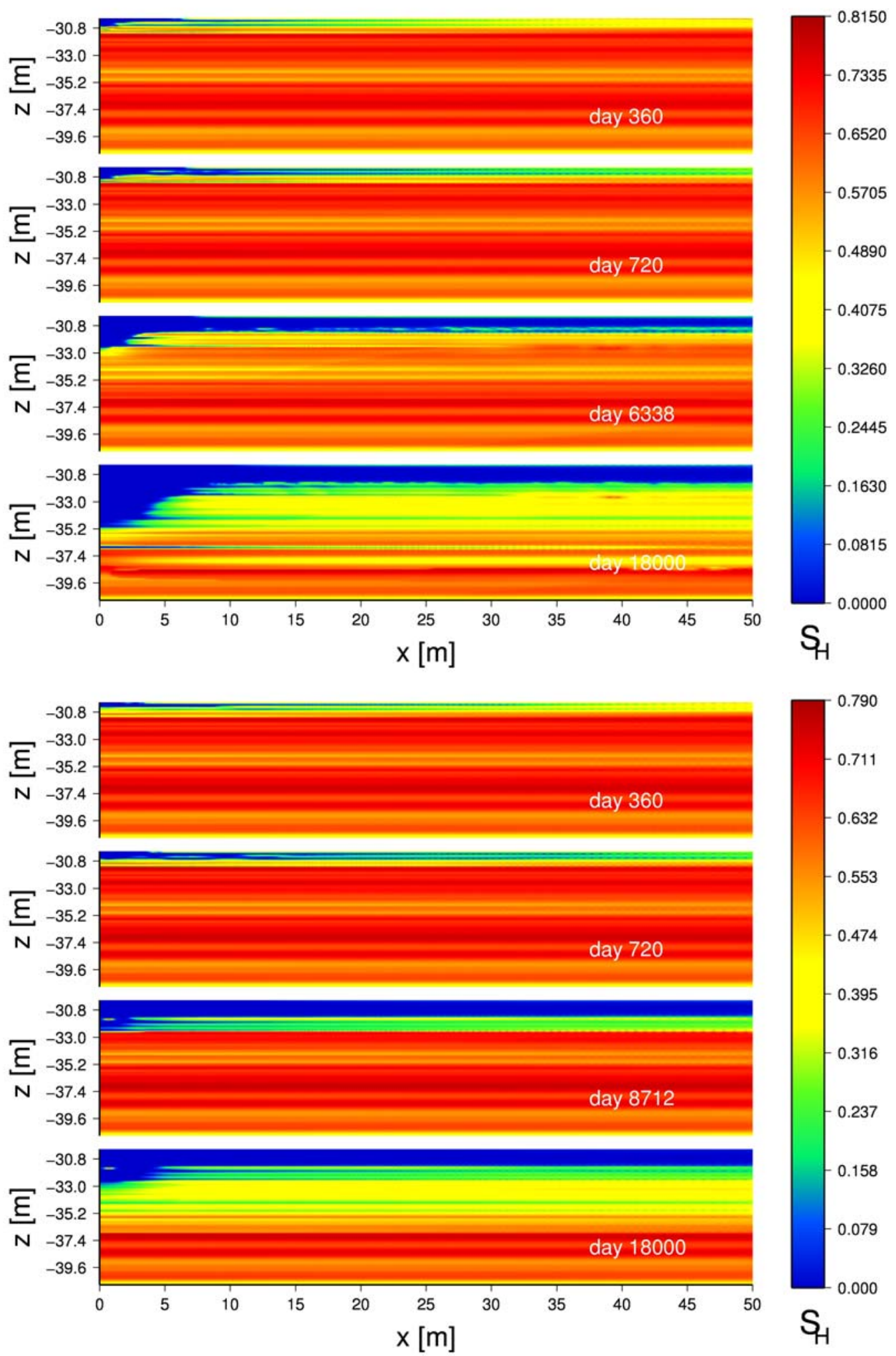

Figure 8. Evolution of $S_{H}$ vs. time for Case $3 \mathrm{a}$ and $3 \mathrm{~b}$, respectively. 

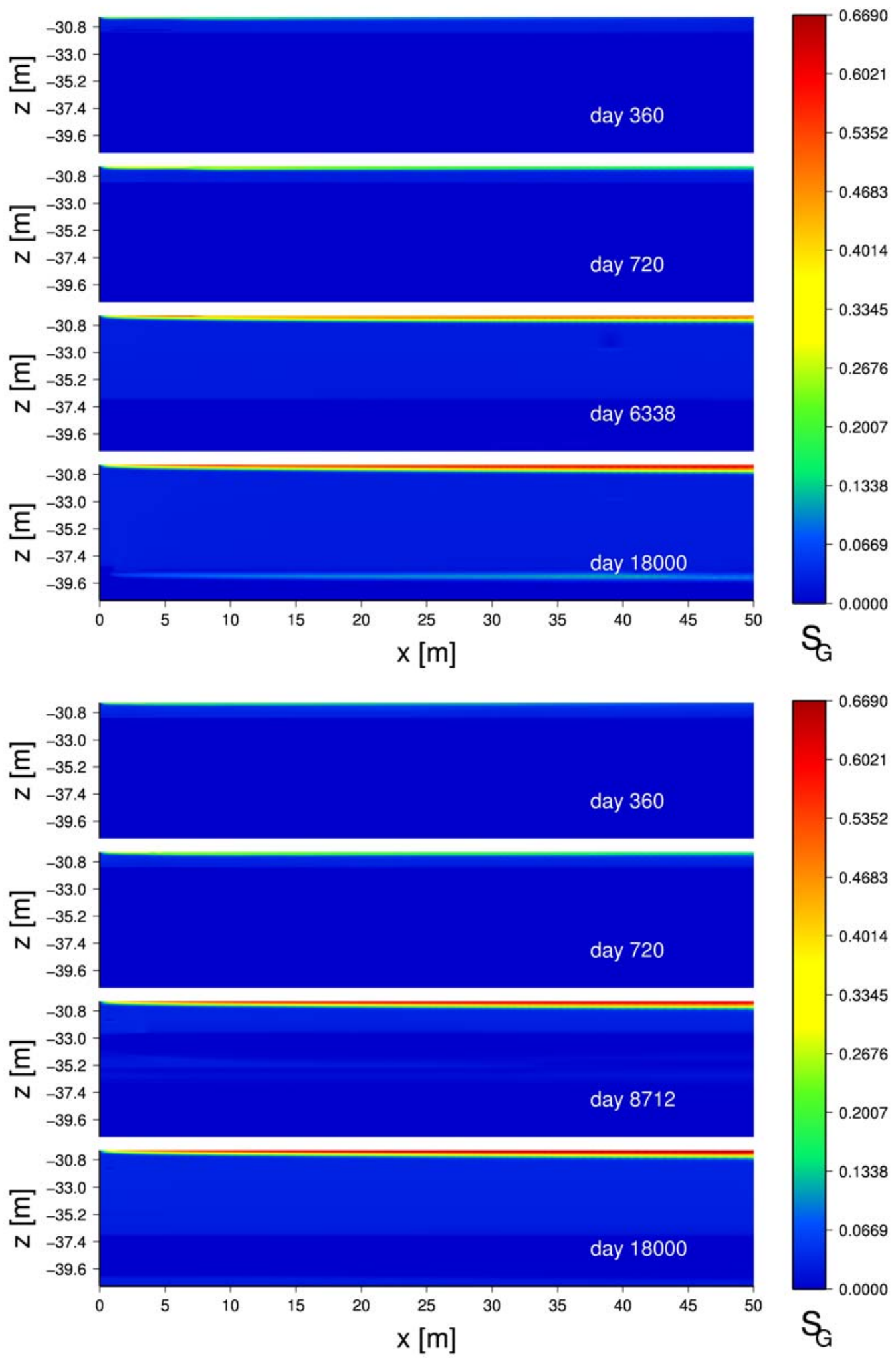

Figure 9. Evolution of $S_{G}$ vs. time for Case $3 \mathrm{a}$ and $3 \mathrm{~b}$, respectively. 

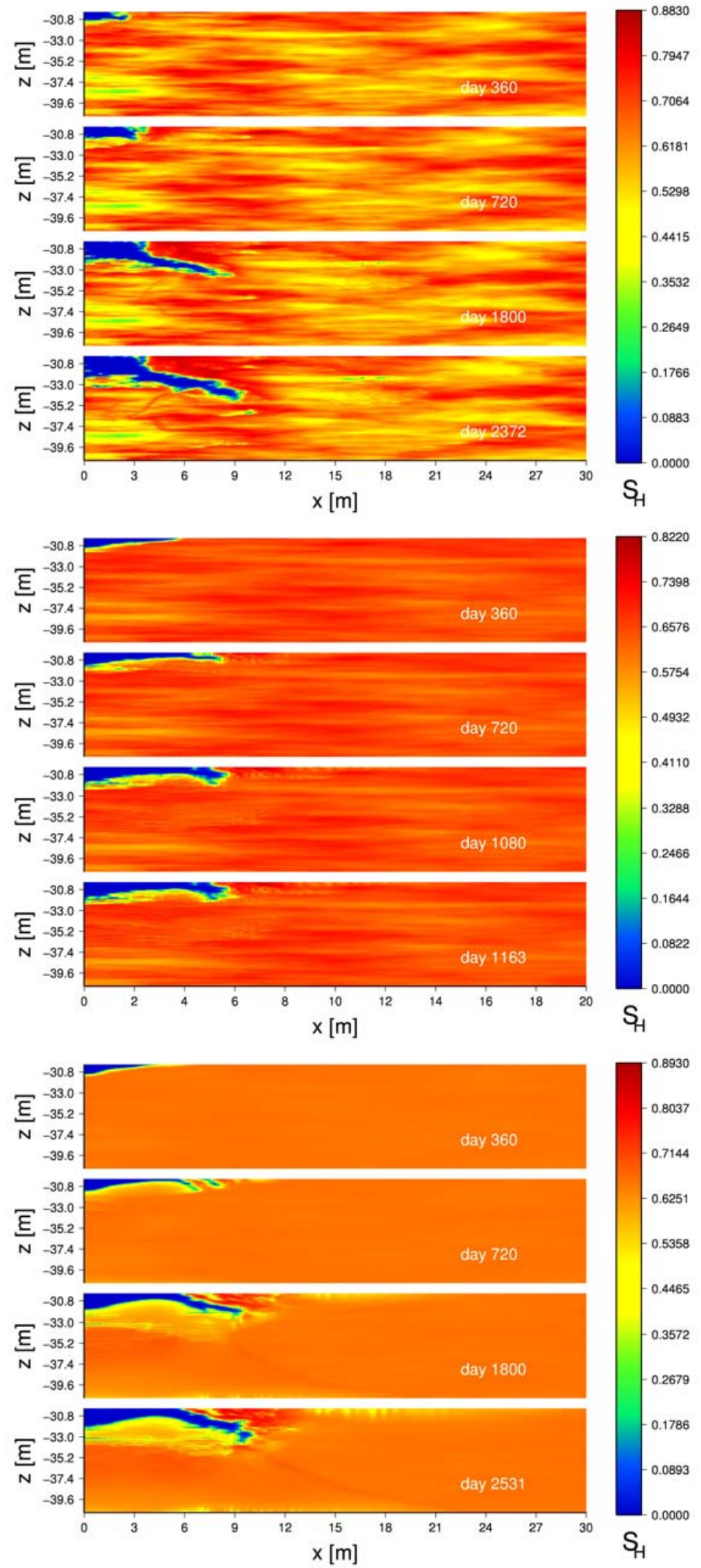

Figure 10. Evolution of $S_{H}$ for Cases $4 \mathrm{a}, 4 \mathrm{~b}$, and $4 \mathrm{c}$, respectively. 

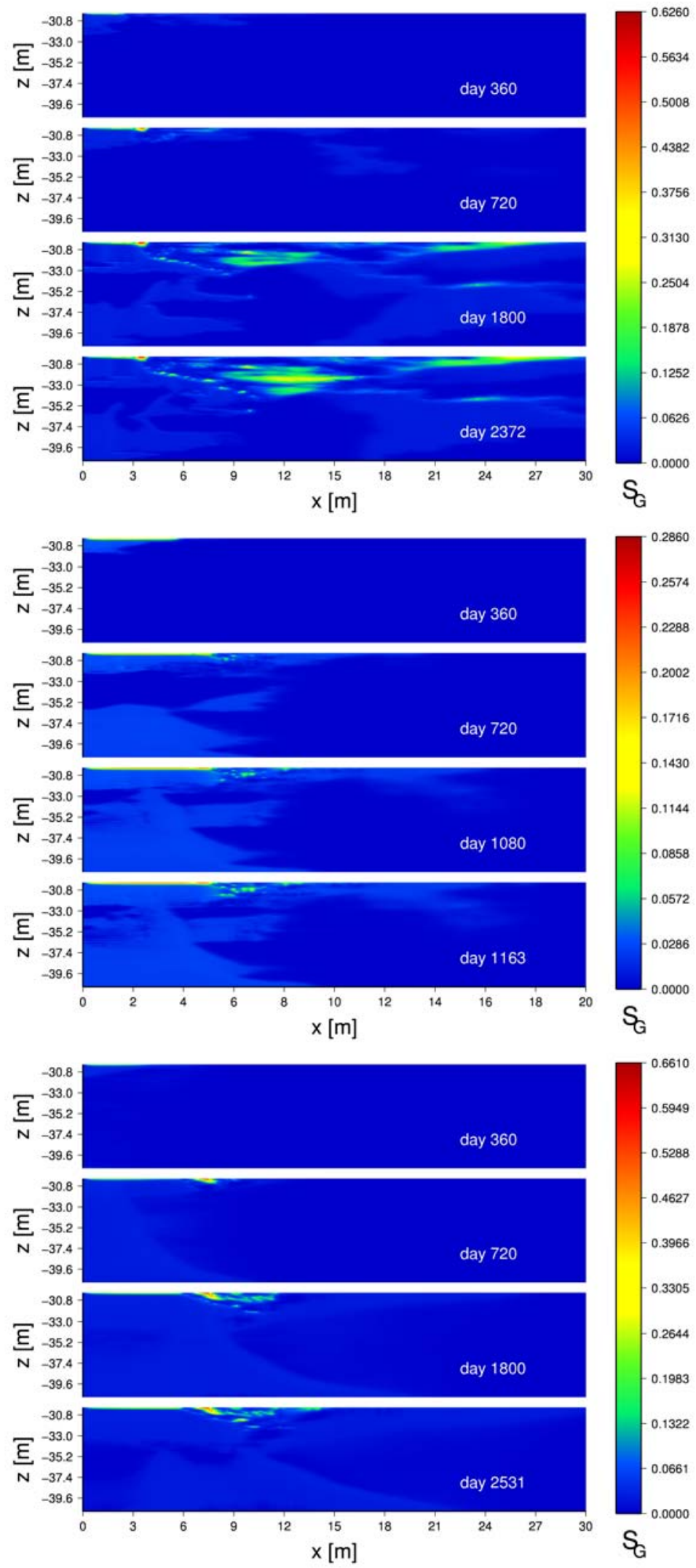

Figure 11. Evolution of $S_{G}$ for Cases $4 \mathrm{a}, 4 \mathrm{~b}$, and $4 \mathrm{c}$, respectively. 


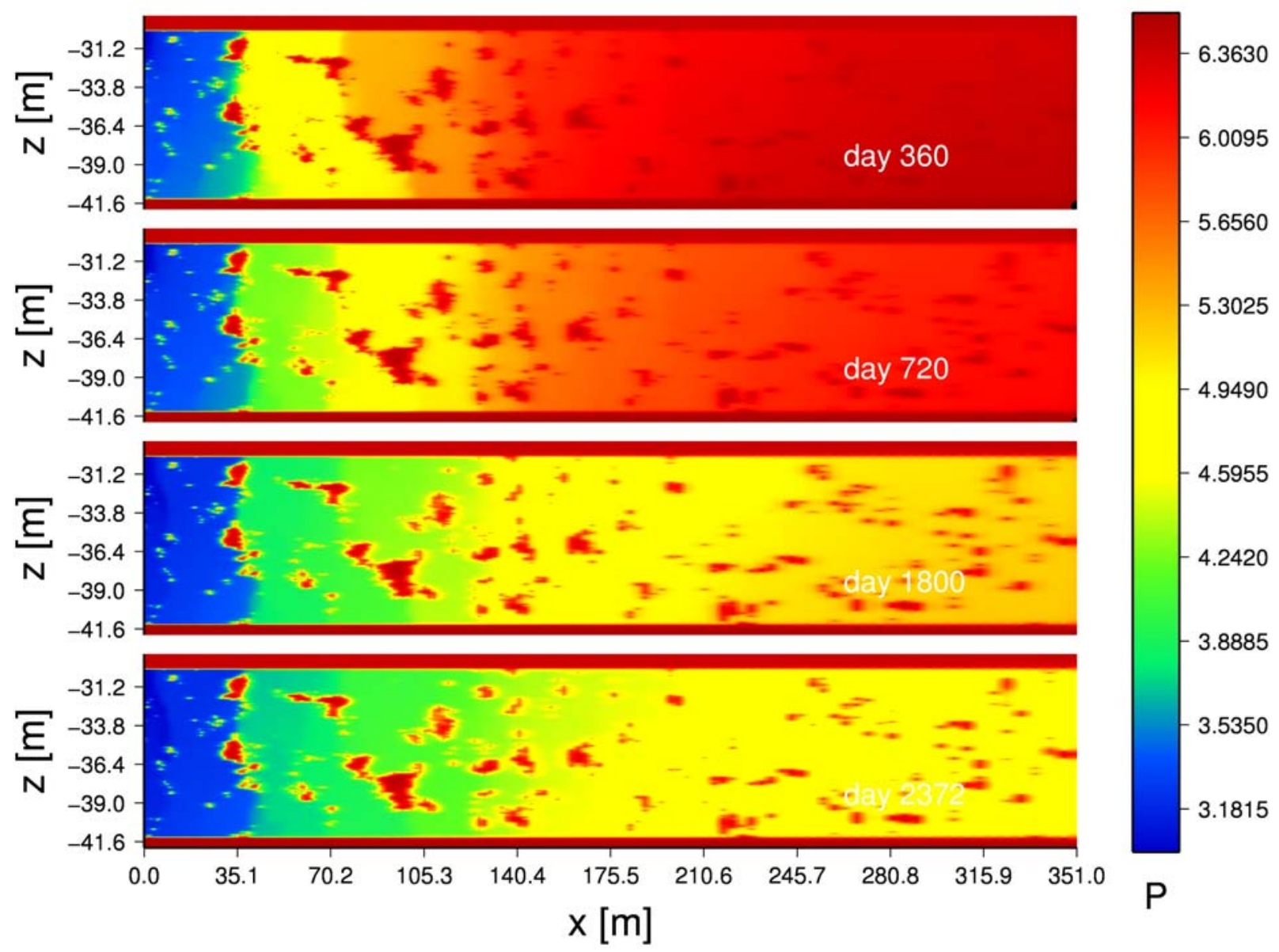

Figure 12. Evolution of pressure, $P(\mathrm{MPa})$, for Case $4 \mathrm{a}$ (note that the horizontal scale encompasses the full width of the deposit, and the vertical scale includes $1 \mathrm{~m}$ each of the overburden and underburden). 


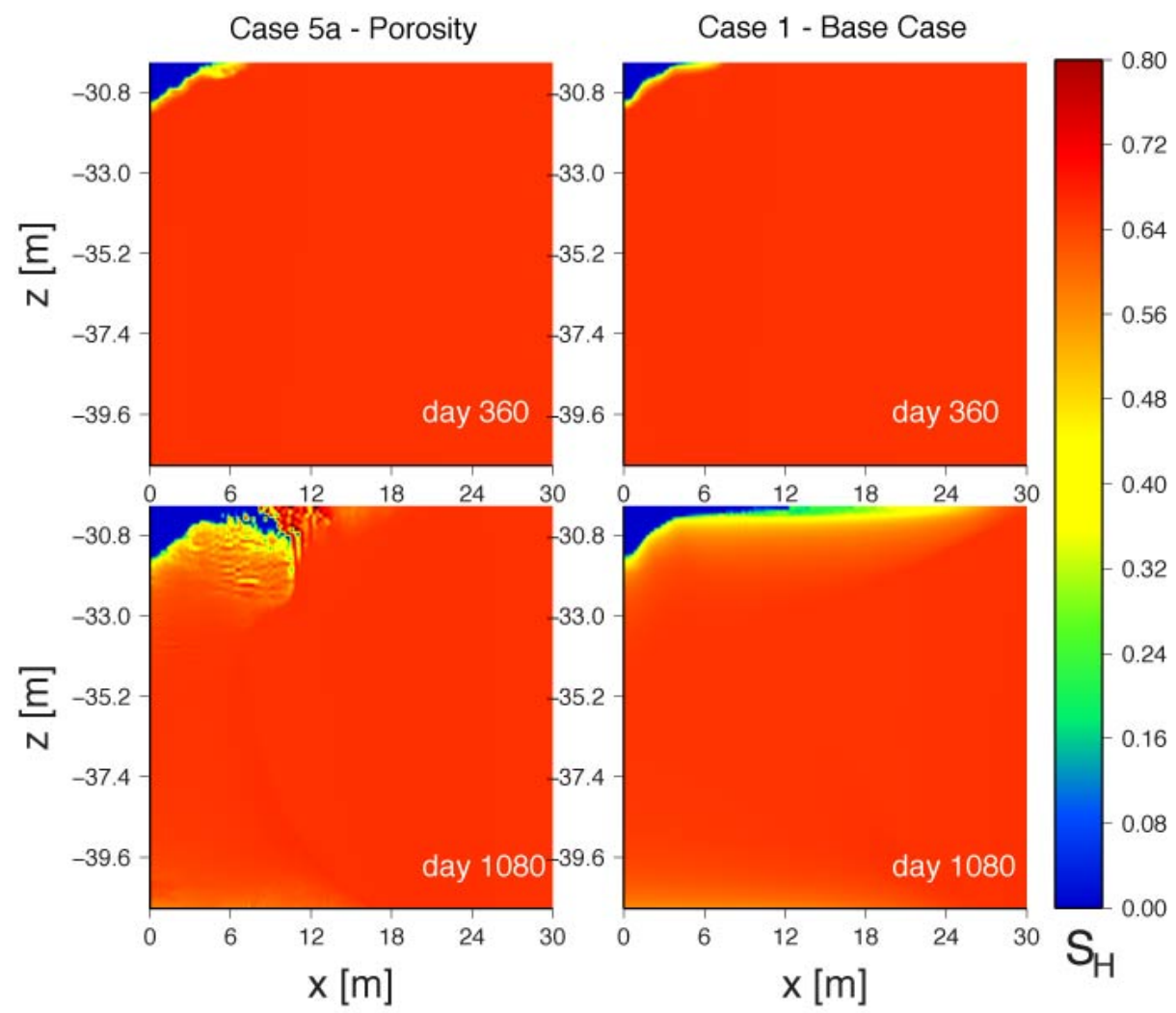

Figure 13. Comparison of the evolution of $S_{H}$ for Case 5a vs. the Base Case. 


\section{DISCLAIMER}

This document was prepared as an account of work sponsored by the United States Government. While this document is believed to contain correct information, neither the United States Government nor any agency thereof, nor The Regents of the University of California, nor any of their employees, makes any warranty, express or implied, or assumes any legal responsibility for the accuracy, completeness, or usefulness of any information, apparatus, product, or process disclosed, or represents that its use would not infringe privately owned rights. Reference herein to any specific commercial product, process, or service by its trade name, trademark, manufacturer, or otherwise, does not necessarily constitute or imply its endorsement, recommendation, or favoring by the United States Government or any agency thereof, or The Regents of the University of California. The views and opinions of authors expressed herein do not necessarily state or reflect those of the United States Government or any agency thereof or The Regents of the University of California.

Ernest Orlando Lawrence Berkeley National Laboratory is an equal opportunity employer. 